\title{
Calagem e adubação boratada na produção de feijoeiro ${ }^{1}$
}

\author{
Liming and fertilization with boron in production of bean
}

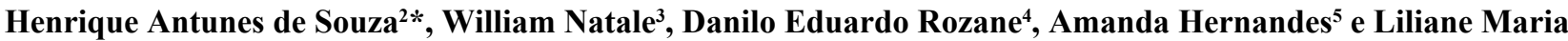 \\ Romualdo $^{6}$
}

\begin{abstract}
Resumo - Objetivou-se avaliar os efeitos da aplicação de calcário e boro nos atributos químicos de um Latossolo, estado nutricional e produtividade da cultura do feijoeiro. As doses de calcário empregadas foram crescentes, considerando-se a saturação por bases igual a 70\%, correspondendo às doses: zero; 0,$6 ; 1,2(\mathrm{v}=70 \%) ; 1,8$ e 2,4 $\mathrm{t} \mathrm{ha}^{-1}$. O calcário utilizado apresentava poder relativo de neutralização total (PRNT), poder de neutralização (PN) e reatividade (RE) de $131 ; 137$ e $95 \%$,

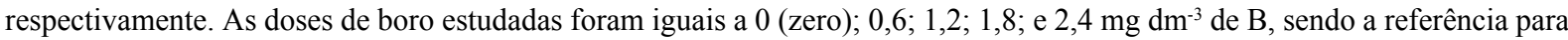
definição das mesmas a de $1,2 \mathrm{mg} \mathrm{dm}^{-3} \mathrm{de} \mathrm{B}$ (ou 1,2 $\mathrm{kg} \mathrm{ha}^{-1} \mathrm{de} \mathrm{B}$ ). Utilizou-se como fonte o ácido bórico $\left(\mathrm{H}_{3} \mathrm{BO}_{3}\right)$ p.a. (17\% B). $\mathrm{Na}$ época do florescimento foi avaliado o estado nutricional das plantas e, aos 90 dias foram avaliadas a fertilidade do solo e a produção de grãos. No solo houve melhoria dos atributos $\mathrm{pH}, \mathrm{SB}, \mathrm{V}$ e na concentração de $\mathrm{Ca}$ e $\mathrm{Mg}$, e do $\mathrm{B}$ com o emprego da adubação boratada. A interação da calagem com a adubação boratada promoveu maior acúmulo de $\mathrm{Ca}, \mathrm{Mg}$ e $\mathrm{B}$ nas plantas. Os dados apresentados demonstram que o feijoeiro foi responsivo à calagem e à adubação boratada, tendo atingido bons índices de produção com a utilização de $1,8 \mathrm{~kg} \mathrm{ha}^{-1}$ de $\mathrm{B}$ com doses crescentes de calcário.
\end{abstract}

Palavras-chave - Phaseolus vulgaris L. Solo tropical. Calcário. Boro.

\begin{abstract}
The objective was to study the application of lime and boron on the chemical in an Oxisol in the nutritional status and yield. The doses of limestone were increasing, considering the saturation of bases $70 \%$, corresponding doses: zero, 0.6 ; 1.2 (saturation of bases $=70 \%$ ), 1.8 and $2.4 \mathrm{t} \mathrm{ha}^{-1}$, respectively. The lime used had relative power of total neutralization $(\mathrm{PRNT})=131 \%$ (neutralization power, $\mathrm{PN}=137 \%$ and reactivity, $\mathrm{RE}=95 \%$ ). The boron doses studied were equal to 0 (zero), $0.6 ; 1.2 ; 1.8$, and $2.4 \mathrm{mg} \mathrm{dm}^{-3}$ of $\mathrm{B}$, with reference to the definition of the same $1.2 \mathrm{mg} \mathrm{dm}^{-3} \mathrm{~B}$ (or $1.2 \mathrm{~kg} \mathrm{ha}^{-1} \mathrm{~B}$ ). It was used as a source boric acid $\left(\mathrm{H}_{3} \mathrm{BO}_{3}\right)(17 \% \mathrm{~B})$. At the time of flowering was assessed the nutritional status of plants and, at 90 days were evaluated soil fertility and yield. There was improvement in soil $\mathrm{pH}$ of the attributes, $\mathrm{SB}, \mathrm{V}$ and the concentration of $\mathrm{Ca}$ and $\mathrm{Mg}$, and $\mathrm{B}$ with the use of boron fertilization. The interaction of lime with boron fertilization increased the concentration of $\mathrm{Ca}, \mathrm{Mg}$ and $\mathrm{B}$ in plants. The data presented demonstrate that the common bean was responsive to liming and boron fertilization, reaching good production rates with the use of $1.8 \mathrm{~kg} \mathrm{ha}^{-1}$ of $\mathrm{B}$ with increasing doses of lime.
\end{abstract}

Key words - Phaseolus vulgaris. Tropical soil. Liming. Boron.

\footnotetext{
*Autor para correspondência

${ }^{1}$ Recebido para publicação em 26/01/2010; aprovado em 28/01/2011

Auxílio pesquisa Fundunesp, Processo no 031/08 DFP

${ }^{2}$ Pesquisador Embrapa Caprinos e Ovinons, Sobral-CE, Brasil, henrique@cnpc.embrapa.br

${ }^{3}$ Departamento de Solos e Adubos, Faculdade de Ciências Agrárias e Veterinárias/Unesp, natale@fcav.unesp.br

${ }^{4}$ Departamento de Solos e Adubos, Faculdade de Ciências Agrárias e Veterinárias/Unesp, danilorozane@yahoo.com.br

${ }^{5}$ Faculdade de Ciências Agrárias e Veterinárias/Unesp, amahernandes@hotmail.com

${ }^{6}$ Faculdade de Zootecnia e Engenharia de Alimentos/USP, lilianeromualdo@yahoo.com.br
} 


\section{Introdução}

O feijão é um dos alimentos básicos da população brasileira, fonte principal de proteína na dieta alimentar dos estratos sociais economicamente menos favorecidos, além de constituir alternativa para exploração agrícola em pequenas propriedades, com ocupação de mão-de-obra menos qualificada. Segundo Rosolem (1987), um dos fatores graves que devem ser levados em conta no plantio do feijoeiro é o sistema radicular pouco profundo. De posse dessa informação vale destacar a importância da calagem, assegurando que as raízes não tenham impedimento químico para a exploração do máximo volume de solo.

Os solos tropicais são naturalmente ácidos em razão da pobreza do material de origem ou devido aos processos de gênese. Além disso, o manejo das áreas agrícolas pode conduzir os solos à acidificação (adubações nitrogenadas, plantios sucessivos, etc.) (QUAGGIO, 2000). Portanto, o correto manejo das culturas, pela correção da fertilidade do solo e do estado nutricional das plantas é fundamental, principalmente para aquelas mais cultivadas como a cultura do feijão. Entre os manejos cita-se a correção da acidez do solo pela calagem e o fornecimento adequado de nutrientes pela adubação, principalmente micronutrientes, entre eles o boro.

A calagem é a maneira mais fácil e barata de elevar o pH do solo, visto ser o calcário o material disponível em maior quantidade no país. As rochas calcárias são constituídas, predominantemente, por carbonatos de cálcio e magnésio, mas também podem conter óxidos e hidróxidos (ERNANI, 2008). O manejo inadequado da calagem pode conduzir à ocorrência de Rhizoctonia solani em feijoeiro, pois, de acordo com Rodrigues et al. (2002), a mudança da natureza álica para eutrófica do solo é um fator que contribui para aumentar a intensidade desta podridão radicular.

Outro aspecto importante dos solos tropicais é a carência de boro (B). A adsorção de B pelos óxidos de Fe e $\mathrm{Al}$ é dependente do $\mathrm{pH}$, sendo a sua disponibilidade maior entre $\mathrm{pH}$ 5,0 e 7,0; diminuindo abaixo e acima desta faixa (ABREU et al., 2007). Em Latossolo Vermelho-Escuro textura argilosa, Fageria (2000) cita que a concentração adequada de B para o feijoeiro seria de $0,9 \mathrm{mg} \mathrm{kg}^{-1}$ e o nível tóxico de $2,8 \mathrm{mg} \mathrm{kg}^{-1}$. Em estudo para avaliação de doses de $\mathrm{B}$, tipos de solo e a aplicação ou não de calcário na cultura da soja, Pegoraro et al. (2008) concluem que a calagem juntamente com a adição de doses de $\mathrm{B}$, a partir de $1,5 \mathrm{mg} \mathrm{dm}^{-3}$ (concentração no solo), aumenta a absorção do micronutriente pelas plantas, mas causa redução na produção de massa de matéria seca da parte aérea nos diversos tipos de solos avaliados (textura arenosa, textura média e textura argilosa). Kikut et al. (2006) salienta que a adubação interfere de maneira diferenciada na qualidade fisiológica de grãos/sementes de feijoeiro.
Objetivou-se, neste trabalho, estudar os efeitos da aplicação de calcário e adubação boratada nos atributos químicos de um Latossolo, no estado nutricional e na produtividade do feijoeiro.

\section{Material e métodos}

O experimento foi desenvolvido em condições de casa de vegetação, em Jaboticabal (SP), empregando-se sementes de feijoeiro (Phaseolus vulgaris L.), cv. BRS Talismã, como planta teste. Utilizou-se amostra do subsolo de um Latossolo Vermelho-Escuro distrófico A moderado, textura argilosa, relevo plano, proveniente de Jaboticabal, com as seguintes coordenadas geográficas $21^{\circ} 15^{\prime} \mathrm{Sul}, 48^{\circ} 18^{\prime}$ ' Oeste e altitude de $603 \mathrm{~m}$, cuja análise química para fins de fertilidade do solo é apresentada na Tabela 1.

$\mathrm{O}$ delineamento experimental foi em blocos casualizados, em esquema fatorial 5 x 5 , com quatro repetições. Cada parcela era composta por duas plantas, que foram cultivadas em vasos de polietileno com capacidade de $3 \mathrm{dm}^{-3}$, conforme Mariano et al. (1999). Foram empregadas 10 sementes por vaso, a fim de obter o stand de 2 plantas por vaso, sendo o desbaste realizado no estágio $\mathrm{V}_{2}$ (desdobramento das folhas primárias).

As doses de calcário empregadas foram crescentes, considerando-se a saturação por bases igual a 70\%, indicada como adequada para a cultura do feijão (AMBROSANO et al., 1997), sendo calculadas como segue: $\mathrm{D}_{0}=$ zero de calcário; $\mathrm{D}_{1}=$ metade da dose para elevar $\mathrm{V}=70 \% ; \mathrm{D}_{2}=$ a dose para elevar $\mathrm{V}=70 \% ; \mathrm{D}_{3}=$ uma vez e meia a dose para elevar $\mathrm{V}=70 \%$; e, $\mathrm{D}_{4}=$ duas vezes a dose para elevar $\mathrm{V}=70 \%$, correspondendo às doses: zero; 0,$6 ; 1,2 ; 1,8$; e $2,4 \mathrm{t} \mathrm{ha}^{-1}$, respectivamente. O calcário utilizado apresentava os seguintes atributos: PRNT (poder relativo de neutralização total) $=131 \%$, $\mathrm{CaO}=420 \mathrm{~g} \mathrm{~kg}^{-1} ; \mathrm{MgO}=250 \mathrm{~g} \mathrm{~kg}^{-1} ; \mathrm{PN}$ (poder de neutralização $)=137 \%$ e RE $($ reatividade $)=95 \%$.

A dose padrão de $B$ foi igual a $1,2 \mathrm{mg} \mathrm{dm}^{-3}$ (ou $\mathrm{kg} \mathrm{ha}^{-1}$ ) indicada por Mariano et al. (1999), que trabalharam com B em feijoeiro em solos de Minas Gerais. Assim, para compor os tratamentos, foram utilizadas: $\mathrm{D}_{0}=$ zero de $\mathrm{B} ; \mathrm{D}_{1}=$ metade da dose padrão; $\mathrm{D}_{2}=$ a dose padrão; $\mathrm{D}_{3}=$ uma vez e meia a dose padrão; e, $\mathrm{D}_{4}=$ duas vezes a dose padrão, correspondendo às seguintes doses: zero; 0,$6 ; 1,2 ; 1,8$ e 2,4 $\mathrm{mg} \mathrm{dm}^{-3} \mathrm{de} \mathrm{B}$, respectivamente. Utilizou-se como fonte o ácido bórico $\left(\mathrm{H}_{3} \mathrm{BO}_{3}\right)$ p.a. $(17 \% \mathrm{~B})$.

As amostras de solo foram incubadas com calcário, nos respectivos tratamentos, em sacos plásticos abertos, durante 30 dias, mantendo-se a umidade em $40 \%$ do VTP, sendo o revolvimento e a homogeneização do solo realizados periodicamente. Em todos os tratamentos o 
Tabela 1 - Atributos de fertilidade do solo determinados a partir de amostra de um Latossolo Vermelho-Escuro, utilizado no experimento

\begin{tabular}{|c|c|c|c|c|c|c|c|c|c|c|}
\hline \multirow{2}{*}{$\mathrm{pH}\left(\mathrm{CaCl}_{2}\right)$} & $\mathrm{MO}^{1}$ & $\mathrm{P}($ resina $)$ & $\mathrm{K}$ & $\mathrm{Ca}$ & $\mathrm{Mg}$ & $\mathrm{H}+\mathrm{Al}$ & $\mathrm{SB}^{2}$ & $\mathrm{CTC}^{3}$ & $\mathrm{Al}$ & $\mathrm{V}$ \\
\hline & $\mathrm{g} \mathrm{dm}^{-3}$ & $\mathrm{mg} \mathrm{dm} \mathrm{m}^{-3}$ & \multicolumn{7}{|c|}{-------------------- $\mathrm{mmol}_{\mathrm{c}} \mathrm{dm}^{-3}$------------------- } & $\%$ \\
\hline 4,3 & 5 & 3 & 1 & 4 & 2 & 23 & 7 & 32 & 4 & 22 \\
\hline \multirow[t]{2}{*}{$\mathrm{B}$} & \multicolumn{2}{|c|}{$\mathrm{Cu}$} & $\mathrm{Fe}$ & \multicolumn{2}{|c|}{$\mathrm{Mn}$} & \multicolumn{2}{|c|}{$\mathrm{Zn}$} & \multicolumn{3}{|c|}{${\mathrm{S}-\mathrm{SO}_{4}^{2-}}^{2-}$} \\
\hline & \multicolumn{2}{|c|}{----------- } & --- & 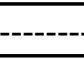 & $\mathrm{mg} \mathrm{c}$ & 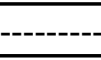 & - & 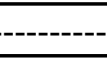 & -1--- & \\
\hline 0,12 & \multicolumn{2}{|c|}{0,2} & 5 & \multicolumn{2}{|c|}{3,4} & \multicolumn{2}{|c|}{0,1} & \multicolumn{2}{|r|}{35} & \\
\hline
\end{tabular}

${ }^{1}$ M.O.: matéria orgânica; ${ }^{2} \mathrm{SB}$ : soma de bases $\rightarrow \mathrm{SB}=\mathrm{Ca}+\mathrm{Mg}+\mathrm{K} ;{ }^{3} \mathrm{CTC}$ : capacidade de troca de cátions a pH 7,0

solo após a incubado foi peneirado e recebeu a adubação básica de semeadura: $128 \mathrm{mg} \mathrm{dm}^{-3} \mathrm{de} \mathrm{N} ; 300 \mathrm{mg} \mathrm{dm}^{-3} \mathrm{de}$ $\mathrm{P} ; 100 \mathrm{mg} \mathrm{dm}^{-3} \mathrm{de} \mathrm{K} ; 30 \mathrm{mg} \mathrm{dm}^{-3}$ de S; $1,5 \mathrm{mg} \mathrm{dm}^{-3}$ de Cu e 5,0 $\mathrm{mg} \mathrm{dm}^{-3}$ de $\mathrm{Zn}$, além das respectivas doses de boro (tratamentos). A adubação de cobertura foi parcelada em três vezes, nos seguintes estágios: V3, V4 e R1 com $110 \mathrm{mg} \mathrm{dm}^{-3}$ de $\mathrm{N}$ e $70 \mathrm{mg} \mathrm{dm}^{-3}$ de $\mathrm{K}$. As fontes utilizadas foram sais p.a.: nitrato de amônio, nitrato de potássio, fosfato monoamônico, cloreto de potássio, sulfato de magnésio, sulfato de cobre e sulfato de zinco, conforme Mariano et al. (1999). A umidade do solo durante o período experimental foi mantida em torno de $70 \%$ do VTP (volume total de poros), por meio de pesagens diárias dos vasos e adição de água deionizada.

No momento do florescimento, foi realizada a coleta de uma planta por vaso para a determinação do estado nutricional do feijoeiro (parte aérea), segundo a metodologia de Bataglia et al. (1983). De posse dos valores de massa de matéria seca e teor dos nutrientes na planta calculou-se, também, o acúmulo dos elementos na parte aérea.

A outra planta foi conduzida até a produção de grãos, que foram colhidos na maturação fisiológica (estádio R9), determinando-se a massa de grãos, o número de vagens por planta e o número de grãos por vagem.

$\mathrm{Na}$ mesma época da colheita dos grãos (90 dias após o plantio), foram realizadas amostragens de solo, que foram analisadas para fins de avaliação da fertilidade de acordo com Raij et al. (2001).

Os resultados foram submetidos às análises de variância e, quando necessário à análise de regressão para doses de calcário e de B. As análises estatísticas foram realizadas com auxílio do software estatístico SISVAR (FERREIRA, 2008).

\section{Resultados e discussão}

\section{Atributos químicos do solo}

Os valores de $\mathrm{pH}, \mathrm{H}+\mathrm{Al}, \mathrm{V}$ e $\mathrm{B}$ foram influenciados tanto pelas doses de calcário, quanto pelas doses de boro, com interação entre ambos os fatores (FIG. 1); enquanto para a M.O., o Ca, o $\mathrm{Mg}$ e a SB houve somente efeito da calagem (FIG. 2).

A calagem ocasionou aumento de $\mathrm{pH}$, independente da dose de boro aplicada (FIG. 1A). A elevação do pH provocada pela calagem reduz a disponibilidade dos micronutrientes catiônicos no solo, aumentando a retenção no complexo coloidal ou reduzindo a solubilidade das formas químicas que controlam a sua concentração na solução do solo (QUAGGIO, 2000).

Houve diminuição da acidez potencial com o incremento das doses de calcário, independentemente da dose de B empregada (FIG. 1B). Esses resultados corroboram os de Moraes et al. (1998) que, estudando a aplicação de calcário na cultura do feijão, constataram diminuição da acidez potencial com o uso do corretivo.

A saturação por bases aumentou em função da calagem, independentemente das doses de boro empregadas (FIG. 1C). A saturação por bases é função da soma de bases, que foi afetada pela calagem (FIG. 2D), e que tem relação direta com os elementos $\mathrm{Ca}$ e $\mathrm{Mg}$, que também sofreram influência da aplicação de calcário (FIG. 2B,C). Alia-se também a diminuição da acidez potencial, a qual compõe a capacidade de troca catiônica juntamente com a soma de bases, assim, influenciando na saturação por bases.

Para as três maiores doses de B empregadas $(1,2 ; 1,8 \mathrm{e}$ $2,4 \mathrm{~kg} \mathrm{ha}^{-1}$ ) houve interação significativa para a concentração desse micronutriente no solo, tendo-se como melhor modelo de resposta o linear crescente (FIG. 1D). A partir do uso da dose de $1,8 \mathrm{~kg} \mathrm{ha}^{-1}$ foi possível obter concentração superior a $0,20 \mathrm{mg} \mathrm{dm}^{-3}$, limite de B considerado baixo para o estado de São Paulo (RAIJ et al., 1997).

A matéria orgânica diminuiu em função das doses de calcário, após 90 dias de condução da cultura (FIG. 2A). Em solos corrigidos, a decomposição da matéria orgânica ocorre mais rapidamente, liberando $\mathrm{N}$ para as plantas; porém, tal afirmação é ponto de controvérsia (QUAGGIO, 2000). 

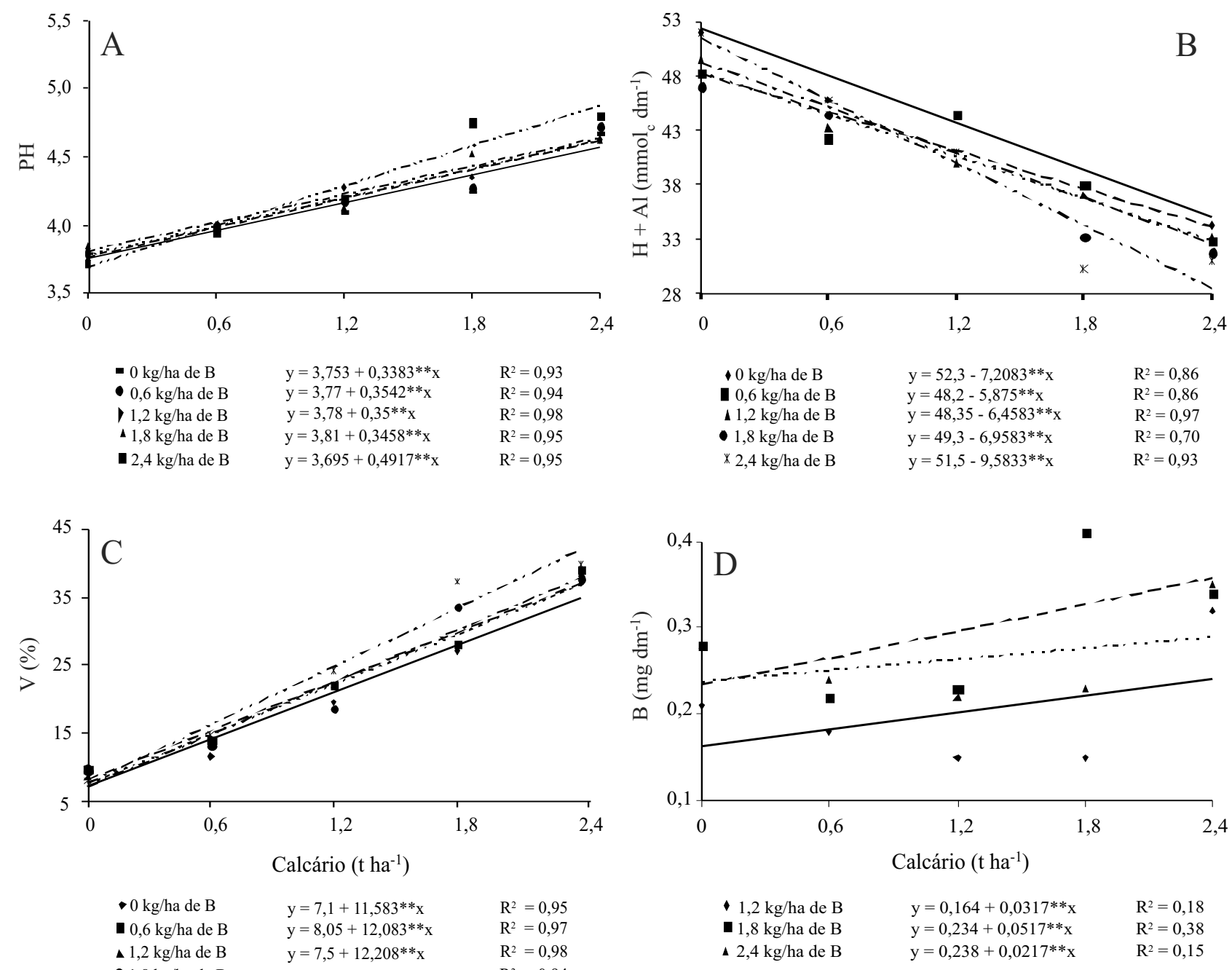

Figura 1 - pH do solo (A), acidez potencial (B), saturação por bases (C) e concentração de boro (D) em função da aplicação de calcário e adubação boratada. *: $\mathrm{P}<0,05 ; * *$ : $<<0,01$

Houve aumento na concentração de $\mathrm{Ca}$ e $\mathrm{Mg}$, com a elevação das doses de calcário (FIG. 2B,C). Isso ocorreu devido a constituição dos corretivos da acidez, os quais possuem $\mathrm{Ca}$ e $\mathrm{Mg}$ em sua composição. Segundo Ernani (2008), a calagem eleva as concentrações de cálcio e magnésio no solo e aumenta a CTC efetiva.

Em estudo avaliando a relação entre cálcio e magnésio na CTC de Latossolos cultivados com feijoeiro, Oliveira e Parra (2003) constataram ausência de resposta das plantas às variações na relação Ca:Mg do solo, tanto no rendimento de massa da matéria seca no estádio de florescimento, quanto na produção de grãos, não permitindo o estabelecimento de uma relação $\mathrm{Ca}: \mathrm{Mg}$ mais apropriada para o cultivo desta espécie no solo.

Para a soma de bases, o melhor modelo de resposta foi o linear crescente, fato este esperado devido ao aumento linear dos dois cátions ( $\mathrm{Ca}$ e $\mathrm{Mg}$ ) que compõe a SB, bem como devido à redução da acidez potencial (FIG. 2D).

\section{Massa de matéria seca e teor de nutrientes na parte aérea}

Não houve interação entre a calagem e a adubação boratada para o teor de nenhum dos nutrientes e para a matéria seca (FIG. 3). Para matéria seca observa-se como melhor modelo de resposta o linear crescente (FIG. 3A); portanto, o aumento das doses de calcário proporcionou incremento na massa das plantas. Os aumentos nos valores de matéria seca decorrente da calagem estão provavelmente relacionados com o crescimento radicular, uma vez que com o maior desenvolvimento das raízes espera-se que ocorra maior absorção de nutrientes (SILVA et al., 2004). 

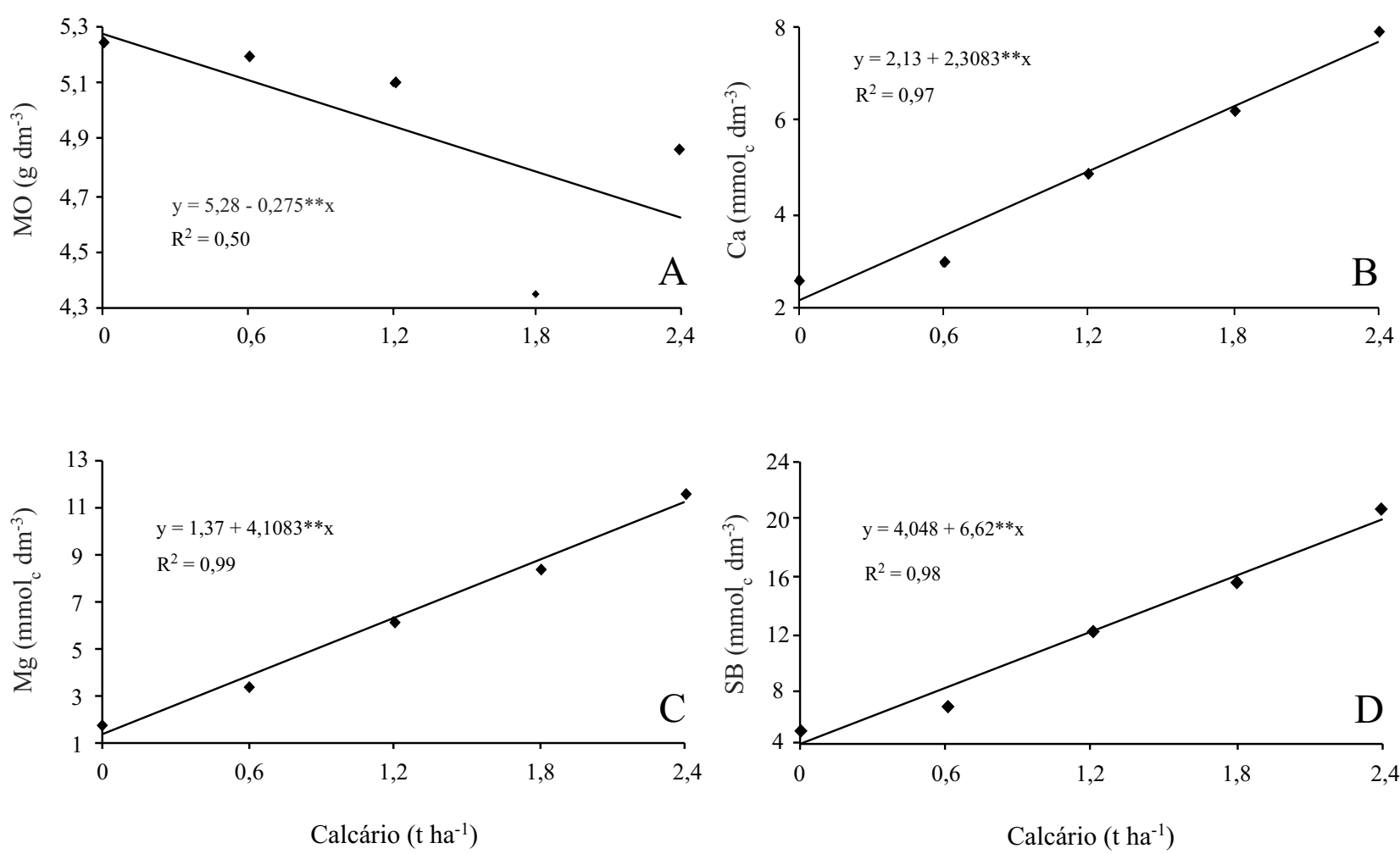

Figura 2 - Matéria orgânica do solo (A), concentração de cálcio (B), concentração de magnésio (C) e soma de bases (D) em função da aplicação de calcário. *: $\mathrm{P}<0,05 ; * *: \mathrm{P}<0,01$
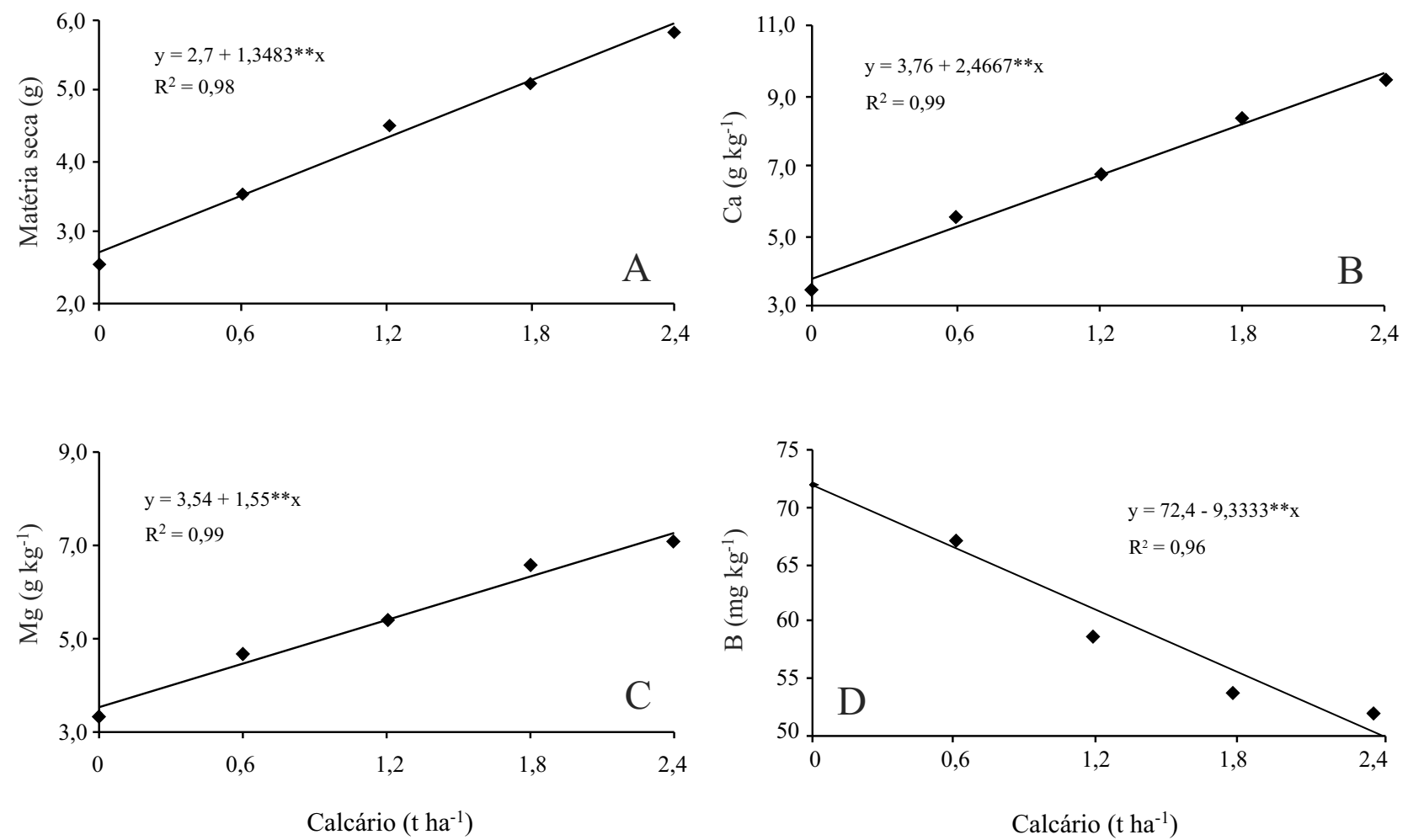

Figura 3 - Matéria seca de plantas de feijão (A) e teores de cálcio (B), magnésio (C) e boro (D) em função de doses de calcário. $*: \mathrm{P}<0,05, * *: \mathrm{P}<0,01$ 
Silva et al. (2007), estudando os efeitos da calagem em diferentes cultivares de feijoeiro, observaram crescimento da massa seca das plantas até a dose de 3,31 t ha-1 de calcário; após esta dose houve decréscimo. O solo utilizado pelos autores foi o Latossolo Vermelho distrófico, com saturação por bases inicial de $3 \%$, e as plantas foram avaliadas até 43 dias após a emergência.

Já para o teor de $\mathrm{Ca}$ e $\mathrm{Mg}$ nas plantas, houve incremento com a calagem (FIG. 3B, C). Tanto no solo, quanto na planta, verificou-se aumento desses macronutrientes em função da calagem. É notório que o calcário, além de corrigir a acidez, é fonte de Ca e de $\mathrm{Mg}$, elementos presentes em sua composição. Assim, a calagem promoveu aumento da massa da matéria seca, bem como do cálcio e do magnésio no solo e nas plantas.

Heinrichs et al. (2008), avaliando a produção do feijoeiro (cv. Pérola) em função de doses de calcário em solo com baixa saturação por bases, observaram aumento tanto nos teores de $\mathrm{Ca}$ como de $\mathrm{Mg}$ nas plantas. Tal fato também foi constatado por Barbosa Filho e Silva (2000). $\mathrm{O}$ aumento do $\mathrm{pH}$ do solo por meio da calagem (FIG. 1A) promoveu, também, aumento da disponibilidade de $\mathrm{Ca}$ e $\mathrm{Mg}$ no solo (FIG. 2B, C), incrementando os teores foliares desses macronutrientes.

O nível de boro nas plantas, em função das doses de calcário, teve comportamento linear decrescente (FIG. 3D). Silva et al. (2007) encontraram resultados semelhantes para alguns cultivares de feijoeiro, sendo a explicação relacionada com a redução da disponibilidade de B sob condição de calagem excessiva (DECHEN; NACHTIGALL, 2006).

$\mathrm{O}$ teor de $\mathrm{Mg}$ também aumentou com as quantidades aplicadas de B no solo (FIG. 4A). O B interfere na absorção e no metabolismo dos cátions
(DECHEN; NACHTIGALL, 2006); essa é a possível explicação para a elevação dos teores de $\mathrm{Mg}$ no feijoeiro, em função das doses do micronutriente.

A adubação com B, como esperado, incrementou o teor desse elemento nas plantas de feijão (FIG. 4B). Apesar de a calagem diminuir a disponibilidade de B, pode-se verificar incremento da massa da matéria seca (FIG. 3A) com o emprego da calagem, ocorrendo efeito de diluição em relação ao B (FIG. 4B).

Mariano et al. (2000) trabalharam com doses de boro em feijoeiro em solos de várzea. Os autores propuseram concentrações de B adequadas para estes solos. Apesar do solo da presente pesquisa ser diferente, verifica-se que as concentrações apresentadas de B, em função da adubação boratada, estiveram acima do nível crítico, tendo como referência a dose padrão $\left(1,2 \mathrm{~kg} \mathrm{ha}^{-1}\right)$, para os seguintes solos: Glei Pouco Húmico, Glei Húmico e Orgânico (FIG. 4B).

\section{Acúmulo de nutrientes na parte aérea}

Houve interação significativa entre calagem e adubação com boro no acúmulo de $\mathrm{Ca}, \mathrm{Mg}$ e $\mathrm{B}$ pelas plantas (FIG. 5 e 6). Dessa forma, verifica-se diferença quanto a significância dos resultados quando se considera isoladamente a massa seca produzida pelo feijoeiro ou os teores dos nutrientes, sendo o acúmulo reflexo de ambos, isto é, da combinação entre massa seca e teor no tecido.

Com o aumento das doses de calcário houve incremento no acúmulo de $\mathrm{Ca}$ e $\mathrm{Mg}$ na parte aérea do feijoeiro, independente da dose de boro empregada (FIG. 5A, B). Isso pode ser explicado, não apenas pelo incremento nos teores de Ca (FIG. 3B) e de Mg (FIG. 3C), devido a esses elementos fazerem parte dos carbonatos presentes no corretivo $\left(\mathrm{CaCO}_{3}+\mathrm{MgCO}_{3}\right)$, mas também, pelo aumento da matéria seca das plantas, conforme observado na Figura 3A.
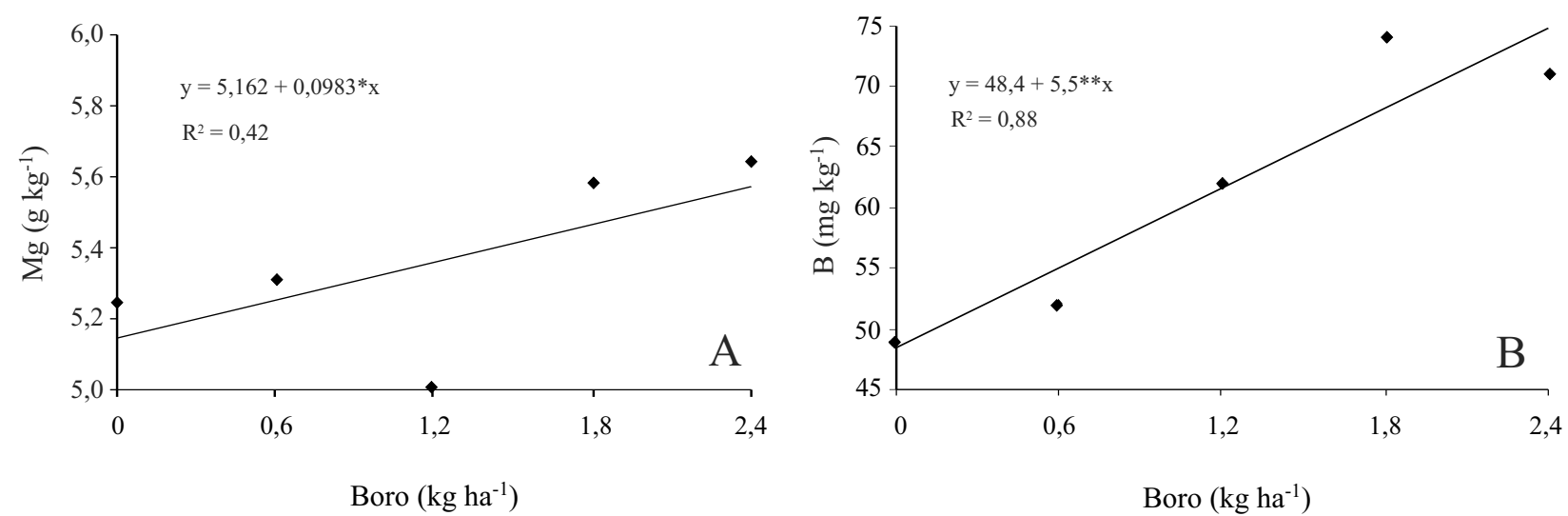

Figura 4 - Teores de magnésio (A) e boro (B) no tecido vegetal do feijoeiro, em função da aplicação de doses de boro. *: P<0,05, $* *: \mathrm{P}<0,01$ 


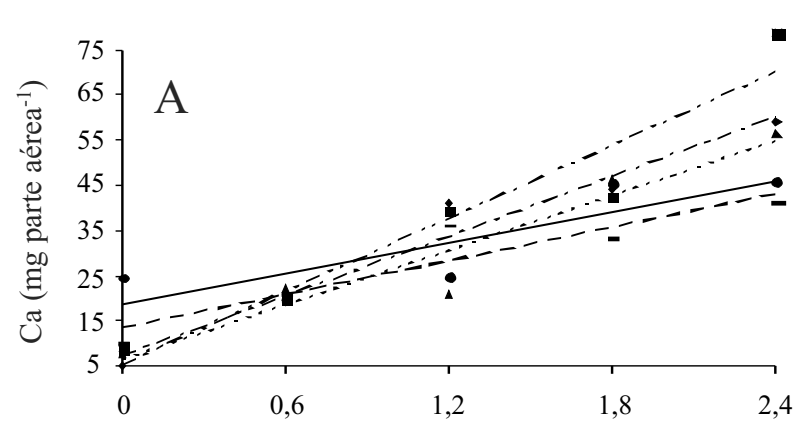

Calcário $\left(\mathrm{t} \mathrm{ha}^{-1}\right)$

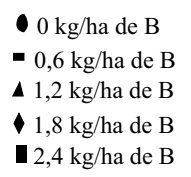

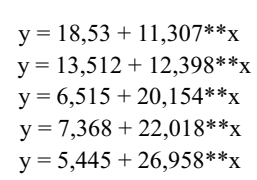

$\mathrm{R}^{2}=0,74$

$\mathrm{R}^{2}=0,87$

$\mathrm{R}^{2}=0,92$

$\mathrm{R}^{2}=0,96$

$\mathrm{R}^{2}=0,92$

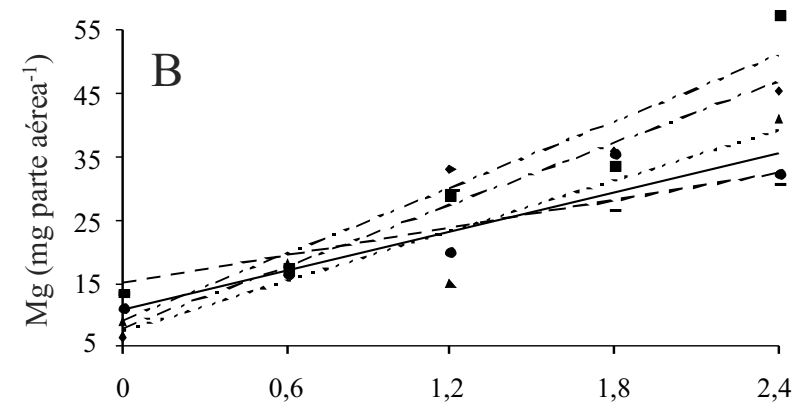

Calcário $\left(\mathrm{t} \mathrm{ha}^{-1}\right)$

Figura 5 - Acúmulo de cálcio (A) e magnésio (B) em plantas de feijoeiro, como resposta a aplicação de doses de calcário e boro. *: $\mathrm{P}<0,05, * *: \mathrm{P}<0,01$

Verifica-se para o boro, entretanto, que houve resultado significativo para a interação (calagem $\mathrm{x}$ adubação com boro), nas duas maiores doses de $\mathrm{B}$ $\left(1,8\right.$ e $\left.2,4 \mathrm{~kg} \mathrm{ha}^{-1}\right)$, sendo que para a primeira o melhor modelo de resposta foi quadrático e para a maior dose deste micronutriente $\left(2,4 \mathrm{~kg} \mathrm{ha}^{-1}\right)$, o melhor modelo de resposta foi o linear crescente. Ou seja, na dose máxima de boro testada a calagem promoveu acúmulo de boro no feijoeiro (FIG. 6). Silva et al. (2007), estudando calagem em feijoeiro, observaram aumento do acúmulo de boro com o incremento das doses de calcário em diferentes cultivares de feijoeiro. Segundo os autores, após a dose de 3,18; 2,88; 2,80 e 3,00 t ha ${ }^{-1}$ nas cultivares Campeão 1, Carioca, FT-Bonito e Pérola, respectivamente, houve diminuição no acúmulo do boro, sendo esses resultados diretamente relacionados com a diminuição do teor deste micronutriente.

\section{Rendimento de grãos}

Houve efeito significativo das doses de calcário no número de vagens por planta (FIG. 7). Para o número de grãos por vagem e peso de grãos por planta, houve interação entre doses de calcário e doses de boro.

Para número de grãos por vagem observa-se que na dose de $1,2 \mathrm{mg} \mathrm{kg}^{-1}$ de $\mathrm{B}$ o melhor modelo de resposta foi o quadrático, com o ponto de máxima em 1,22 $\mathrm{t} \mathrm{ha}^{-1}$ de calcário, para uma produção de 4,68 grãos por vagem (FIG. 8). Na dose de $1,8 \mathrm{mg} \mathrm{kg}^{-1}$ de B o modelo linear crescente foi o que melhor se ajustou aos dados, ou seja, conforme se aumentou a dose de calcário, incrementou o número de grãos por vagem (FIG. 8). Para as demais doses de boro, em função da calagem, não foram encontrados resultados significativos.

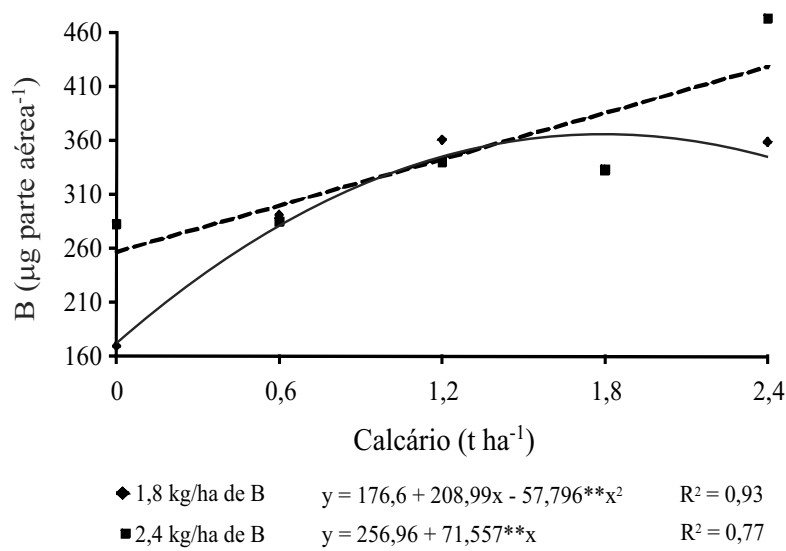

Figura 6 - Acúmulo de boro em plantas de feijoeiro, como resposta a aplicação de doses de calcário e boro. *: $\mathrm{P}<0,05$, **: $\mathrm{P}<0,01$

$\mathrm{Na}$ produção de grãos de feijão por planta verifica-se resultado significativo da interação apenas para as doses de B: 0; 0,6 e 1,8 $\mathrm{kg} \mathrm{ha}^{-1}\left(\mathrm{mg} \mathrm{dm}^{-3}\right)$. Para estas, o melhor modelo de resposta foi o linear crescente (FIG. 9). Em estudo para determinação do nível crítico de $\mathrm{B}$ em solos de várzea de Minas Gerais, foi verificado que a dose que proporcionou maior matéria seca de grãos para o Glei Pouco Húmico foi de 2,79 $\mathrm{mg} \mathrm{dm}^{-3}$ de B; para o Aluvial foi de $2,83 \mathrm{mg} \mathrm{dm}^{-3} \mathrm{de}$ B; para o Glei Húmico foi de 2,52 $\mathrm{mg} \mathrm{dm}^{-3} \mathrm{de} \mathrm{B}$; e para o Orgânico 2,50 $\mathrm{mg} \mathrm{dm}^{-3} \mathrm{de}$ B (MARIANO et al., 1999).

Fageria e Stone (2004), avaliando a aplicação de calcário em Latossolo Vermelho distrófico, constataram que doses de até $12 \mathrm{t} \mathrm{ha}^{-1}$ de calcário aumentam a produtividade de feijoeiro em solo de Cerrado. Fageria 


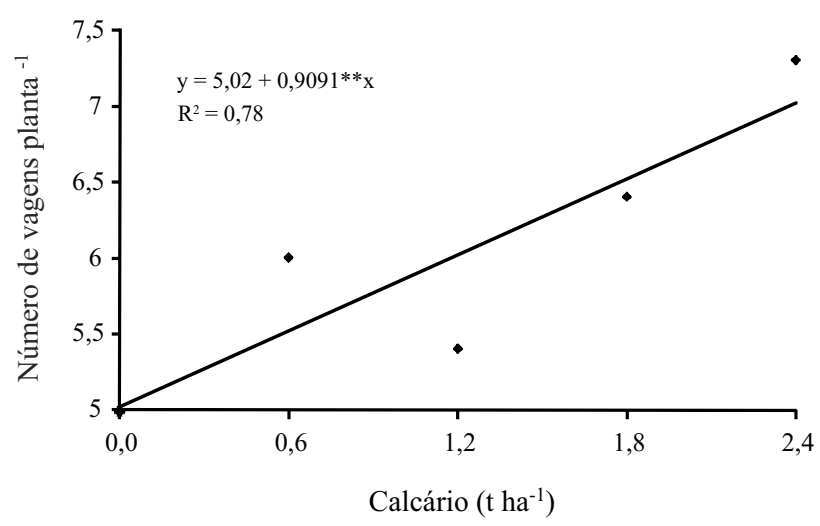

Figura 7 - Efeito de doses de calcário sobre o número de vagens do feijoeiro. *: $\mathrm{P}<0,05, * *: \mathrm{P}<0,01$

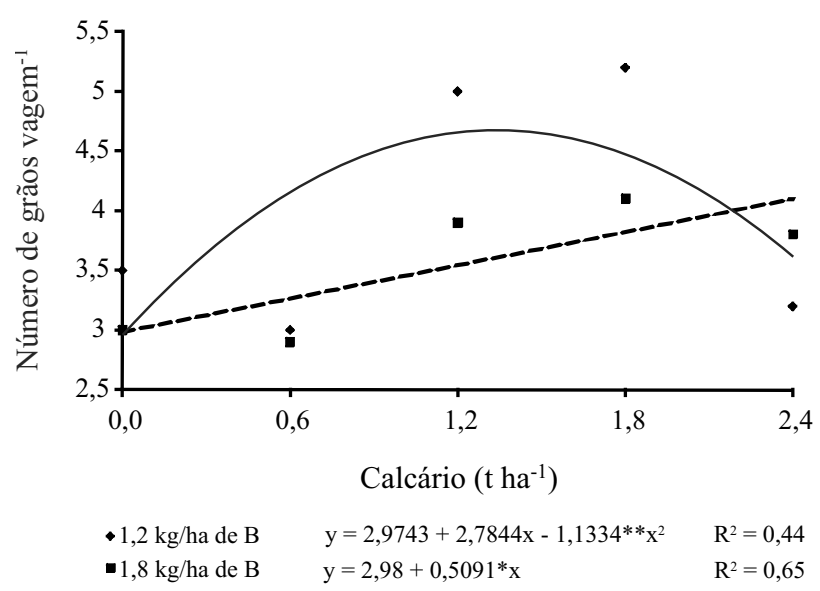

Figura 8 - Efeito de doses de calcário e adubação boratada sobre o número de grãos por vagem em feijoeiro. *: $\mathrm{P}<0,05$, **: $\mathrm{P}<0,01$

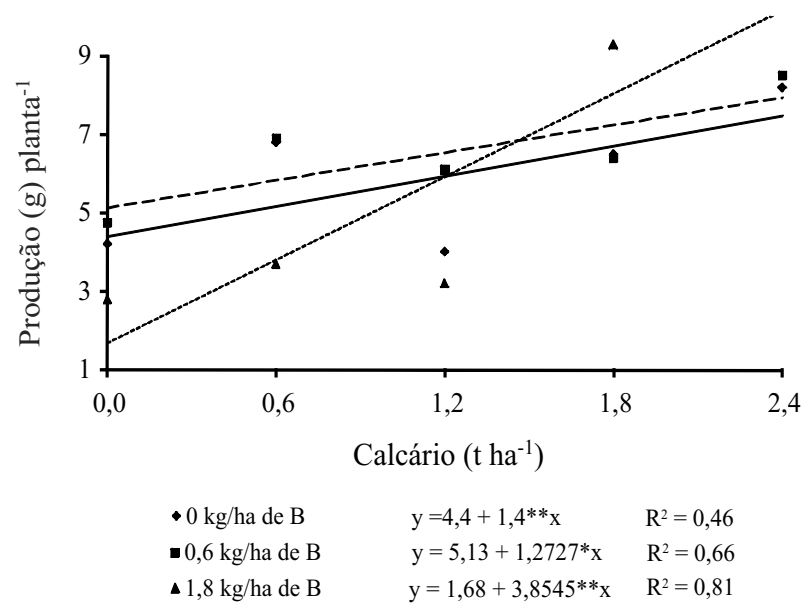

Figura 9 - Efeito de doses de calcário e adubação boratada sobre a produção de grãos em feijoeiro. *: $\mathrm{P}<0,05, * *$ : $\mathrm{P}<0,01$
(2001), em avaliação do efeito da calagem na produção de feijão em solo de Cerrado, constatou que doses de $5 \mathrm{t} \mathrm{ha}^{-1}$ de calcário são suficientes para a obtenção de $90 \%$ da produtividade máxima. Porém, o autor não mencionou a saturação inicial do solo. Verificase desta maneira, que em estudos encontrados na literatura as doses observadas em que houve aumento de produtividade foram além das empregadas neste ensaio.

Com o intuito de se extrair o máximo de informações deste estudo, realizaram-se correlações entre a produção de grãos e a saturação por bases do solo e, entre a produção de grãos e o pH do solo . Tais correlações foram possíveis devido à interação entre a calagem e a adubação boratada terem sido significativas, apresentando como melhor modelo de resposta o linear crescente. Vale ressaltar que as variáveis foram escolhidas por representarem informações pertinentes para a utilização da calagem. A correlação entre a produção de grãos e o $\mathrm{pH}$ foi positiva e significativa a $1 \%(\mathrm{r}=0,45$ e $\mathrm{t}=5,01)$, já a correlação entre produção de grãos e saturação por bases também foi positiva e significativa a $1 \%$ de probabilidade $(\mathrm{r}=0,42$ e $\mathrm{t}=4,05)$. Assim, pode-se considerar que o aumento de produção esteve associado à melhoria destes atributos, proporcionado principalmente pela calagem.

Quando se analisa o efeito da calagem, na realidade está-se analisando um conjunto complexo de fatores, impossíveis de serem isolados, tais como: $\mathrm{pH}$ do solo, disponibilidade de nutrientes e diminuição de efeitos tóxicos (ROSOLEM, 1987).

\section{Conclusões}

1. No solo houve melhora dos atributos $\mathrm{pH}, \mathrm{SB}, \mathrm{V}$ e aumento na concentração de $\mathrm{Ca}$ e $\mathrm{Mg}$, e do B com o emprego da adubação boratada;

2. A interação da calagem com a adubação boratada promove maior acúmulo de $\mathrm{Ca}, \mathrm{Mg}$ e $\mathrm{B}$ nas plantas;

3. O feijoeiro (cv. BRS Talismã) respondeu à calagem e à adubação boratada, tendo atingido bons índices de produção com a utilização de $1,8 \mathrm{~kg} \mathrm{ha}^{-1} \mathrm{de} \mathrm{B}$ com doses crescentes de calcário;

4. Há correlações significativas e positivas entre a produção de grãos, o pH e a saturação por bases.

\section{Agradecimentos}

À Embrapa Arroz e Feijão (CNPAF) de Santo Antônio de Goiás (GO) que cederam as sementes e 
à Fundunesp (Processo $n^{\circ}$ 031/08 DFP) pelo auxílio financeiro na execução do ensaio.

\section{Referências}

ABREU, C. A.; LOPES, A. S.; SANTOS, G. C. G. Micronutrientes. In: NOVAIS, R. F. et al. Fertilidade do solo. Viçosa: SBCS, 2007. p. 724-736.

AMBrosAnO, E. J. et al. Feijão. In: RAIJ, B. Van et al. Recomendações de adubação e calagem para o Estado de São Paulo. 2. ed. Campinas: Instituto Agronômico \& Fundação IAC, 1997. p.194-195. (Boletim Técnico, 100).

BARBOSA FILHO, M. P.; SILVA, O. F. Adubação e calagem para o feijoeiro irrigado em solo de cerrado. Pesquisa Agropecuária Brasileira, v. 35, n. 07, p. 1317-1324, 2000.

BAtaglia, O. C. et al. Métodos de análise química de plantas. Campinas: Instituto Agronômico, 1983. 48p. (Boletim Técnico, 78).

DECHEN, A. R.; NACHTIGALL, G. R. Micronutrientes. In: FERNANDES, M. S. Nutrição mineral de plantas. Viçosa: Sociedade Brasileira de Ciência do Solo, 2006. p. 327-354.

ERNANI, P. R. Química do solo e disponibilidade de nutrientes. Lages: UDESC, 2008. 230p.

FAGERIA, N. K. Efeito da calagem na produção de arroz, feijão, milho e soja em solo de cerrado. Pesquisa Agropecuária Brasileira, v. 36, n. 11, p. 1419-1424, 2001.

FAGERIA, N. K.; STONE, L. F. Produtividade de feijão no sistema de plantio direto com a aplicação de calcário e zinco. Pesquisa Agropecuária Brasileira, v. 39, n. 01, p. 73-78, 2004.

HEINRICHS, R. et al. Atributos químicos do solo e produção do feijoeiro com a aplicação de calcário e manganês. Revista Brasileira de Ciência do Solo, v. 32, n. 03, p. 1157-1164, 2008.

KIKUT, H. Qualidade de sementes de genótipo de feijão em função da adubação. Revista Ciência Agronômica, v. 37, n. 01, p. 37-43, 2006.

MARIANO, E. D. A. et al. Boro em solos de várzea do sul de minas gerais e a cultura do feijoeiro. Scientia Agricola, v. 56, n. 04, p. 1051-1058, 1999. Suplemento.
MARIANO, E. D. et al. Níveis críticos de boro em solos de várzea para o cultivo do feijoeiro. Pesquisa Agropecuária Brasileira, v. 35, n. 08, p. 1637-1644, 2000.

MORAES, J. F. L. et al. Efeito de doses de calcário e de gesso na cultura do feijoeiro (Phaseolus vulgaris L.) cv. Carioca-80. Scientia Agricola, v. 55, n. 03, p. 438-447, 1998.

OLIVEIRA, E. L.; PARRA, M .S. Resposta do feijoeiro a relações variáveis entre cálcio e magnésio na capacidade de troca de cátions de latossolos. Revista Brasileira de Ciência do Solo, v. 27, n. 05, p. 859-866, 2003.

PEGORARO, R. F. et al. Crescimento de soja em solos em resposta a doses de boro, calagem e textura do solo. Ciência $\mathbf{e}$ Agrotecnologia, v. 32, p. 1092-1098, 2008.

QUAGgio, J. A. Acidez e calagem em solos tropicais. Campinas: Instituto Agrnômico, 2000. 111p.

SILVA, L. M. et al. Sistema radicular de cultivares de feijão em resposta à calagem. Pesquisa Agropecuária Brasileira, v. 39, n. 07, p. 701-707, 2004.

SILVA, L. M. et al. Crescimento radicular e absorção de micronutrientes do feijoeiro em razão da calagem. Revista Científica, v. 35, n. 2, p. 88-105, 2007.

FERREIRA, D. F. Sisvar: um programa para análises e ensino estatístico. Revista Científica Symposium, v. 6, n. 2, p. 3641, 2008.

RAIJ, B. van et al. Recomendações de adubação e calagem para o Estado de São Paulo. Campinas: Instituto Agronômico/ Fundação IAC, 1996. 285p. (Boletim Técnico, 100).

RAIJ, B. Van et al. Análise química para avaliação da fertilidade de solos tropicais. 1 ed. Campinas: Instituto Agronômico, 2001. 285p. (Boletim Técnico, 30).

Rodrigues, F. A.; CARVAlho, E. M.; VAle, F. X. R. Severidade da podridão-radicular de Rhizoctonia do feijoeiro influenciada pela calagem, e pelas fontes e doses de nitrogênio. Pesquisa Agropecuária Brasileira, v. 37, n. 9, p. 1247-1252, 2002.

ROSOLEM, C. A. Nutrição e Adubação do Feijoeiro. Piracicaba: Potafós, 1987. 80p. 